\title{
The Role of Open Business Model in Technology Commercialization
}

\author{
Hyo J. Park ${ }^{*} \cdot$ Wan S. Shin ${ }^{* *} \cdot$ Yong J. Ju ${ }^{* * *+}$ \\ ${ }^{*}$ R\&D Strategy Team, Hyundai Steel Company, Dangjin, Korea \\ ** Department of Management of Technology, Sungkyunkwan University, Suwon, Korea \\ *** Department of Railroad Management, Woosong College, Daejeon, Korea
}

\begin{abstract}
Purpose: This paper has examined the impact of open innovation business model in technology commercialization with the data from 30 companies of manufacturing firms in South Korea.

Methods: The findings provide support for distinguishing five hypotheses relating to development time, IP management, sales, firm size and R\&D intensity. To test the hypotheses, data were collected using via e-mail and fax. Small and medium-sized (less than 300 employees) and large industrial firms were chosen for this study.

Results: The result shows that openness in its business model is positively associated with successful technology commercialization.

Conclusion: The major findings and the implications are: First, as the business model gets more open, development period of technology will be more favorable which gets benefit from rising costs of innovation. Second, as the business model gets more open, large portion of sales are created from new products. Thus, the problem of shorter product life in the market which affects large portion of market revenue can be solved through an open business model. Third, in general, R\&D intensity, firm size and the level of IP management affect determination of business model types. The findings also suggest that companies need to increasingly address their external technology exploitation process instead of focusing on their internal innovation processes.
\end{abstract}

Key Words: Open Innovation, Business Model, Technology Commercialization, Intellectual Property Management, Closed Innovation, R\&D Investment

- Received 4 August 2014, revised 28 August 2014, accepted 29 August 2014

† Corresponding Author(yjju@wsi.ac.kr)

(c) 2014, The Korean Society for Quality Management

This is an Open Access article distributed under the terms of the Creative Commons Attribution Non-Commercial License (http://creativecommons.org/licenses/by-nc/3.0) which permits unrestricted non-Commercial use, distribution, and reproduction in any medium, provided the original work is properly cited. 


\section{Introduction}

Technology commercialization is not an option in R\&D for survival in today's competitive markets. The capability of commercializing technology depends on the competence of the firms, which refers to the competence of the firms to use technologies in products across a wider range of markets, incorporate a greater breadth of technologies in products, and get products to market faster (Nevens et al., 1990). The question is how. Innovation activities have frequently been shown to be a key element for increasing the market share, market value as well as the long-term survival prospects of firms (e.g. Banbury and Mitchell, 1995; Brockhoff, 1997; Brockhoff, 1999). According to the 2008 EU industrial R\&D Investment Scoreboard2), based on data collected from 1,000 EU companies and 1,000 non-EU companies, all 2,000 companies increased R\&D investments by $9 \%$ in 2007/8, compared to $10 \%$ in past year's Scoreboard and $7 \%$ in the year before3). Moreover, in Japan, a study by the Cabinet Office (2005) found that the efficiency of private-sector R\&D declined during the 1990s. It seems that the overall output from investment in innovation doesn't reflect the large amount of inputs. Why? As a matter of fact, everyone says innovation is important, but almost no one agrees on the best way to profit from it and remains for many companies an irksome mystery.

Indeed, firms have long faced concerns on how to obtain returns to innovation, particularly when they lack the resources to fully exploit or appropriate the returns (Teece, 1986). From the BCG Innovation 2008 survey, when asked what they thought was preventing their companies from achieving higher returns, based on 3,000 global executives, executives most commonly cited a risk-averse corporate culture (36\%), as well as overly lengthy development times (36\%). Companies have historically relied on large investments in internal research and development (R\&D) to drive innovation and provide sustainable growth. This vertically-integrated model, however, is eroding due to a number of factors. A more open and transnational approach, which Henry Chesbrough named 'open innovation', is emerging as an effective alternative to the closed innovation model. In fact, the open innovation framework helps explain how firms have used the rise of open-resource to develop new forms of innovation strategies. The key tenet of open innovation is that not all good ideas will emerge from inside the organization and not all good ideas generated within the organization can be successfully commercialized by the same firm. Chesbrough (2003a) suggests that many innovative firms have shifted to an 'open innovation' model, using a wide range of external actors and sources to help them achieve and sustain innovation. Indeed, from the survey result4), in 2006, 53 percent of innovative firms have shifted to an 'open innovation'.

To date, open innovation concepts and practices have been explored primarily in the U.S., with comprehensive case studies covering numerous American companies such as P\&G, IBM, Intel and Lucent (Chesbrough, 2003b; 2006). Nevertheless, there is a need for empirical study that has examined the degree

2) The EU Industrial R\&D Investment Scoreboard is published annually by the European Commission (JRCIPTS/DG RTD) as part of its Industrial Research Investment Monitoring and Analysis activity (IRMA). Company data were collected by Company Reporting Ltd.

3) For more information on R\&D investment date, please look at "The 2008 EU Industrial R\&D Investment Scoreboard"

4) Bain \& Company, Management Tools and Trends, 2008 
to which firms follow the open innovation paradigm regarding the acquisition and commercialization of technology assets, prior works in this field are mostly based on theoretical considerations and case studies (Lichtenthaler, 2008b). Moreover, there are no prior works on assessing business models of companies in the perspective of open and closed innovation.

Hence, this paper explores how open business model distinguishes itself from other forms of business model and, first and foremost, finds the role of openness in explaining technology commercialization and the following essential questions arise, which have not been examined in earlier work. Is open innovation really the solution to foster technology commercialization? If so, to what degrees have firms adopted the open business models? What impacts does the open innovation business model have in technology commercialization? These issues are analyzed with data from small and medium-sized and large industrial firms in Korea, which has been conducted to support these complex issues in open innovation paradigm. Accordingly, the aim of this study is to look at how open innovation is being practiced in Korea companies both large and small and find out how risk-averse culture and lead time can be reduced through open innovation and eventually foster technology commercialization through open innovation. Secondly, this study examines how closed and open business model, suggested by Henry Chesbrough, affect R\&D performance such as R\&D intensity, sales, IP management. The first section reviews the previous literature and sets out the hypotheses of this study. Then, the paper presents the empirical results to test the hypotheses. Finally, the last section provides discussion of the findings and the managerial and scholarly implication.

\section{Theoretical Background and Hypotheses}

\subsection{Open Innovation Business Model}

In 2001, envelops tainted with anthrax had spread infection and death through the U.S. postal system. Executives in Pitney Bowes realize that their core business of mailing system is threatened by anthrax. It was chaos for corporations and mailing services where they had to find solution that could protect people from the deadly virus. Pitney Bowes's core competence was in the area of secure metering systems that protected postal revenue; the $\$ 4.1$ billion market leader had nothing in its pipeline to shield clients against a biological threat as unexpected as anthrax (Rigby et al., 2002). Pitney Bowes decided to look for ideas outside because they have to respond fast and effectively to the problems. With help from the outside inventors, Pitney Bowes was able to introduce new products and services effectively to secure the mail against bioterrorism (Rigby et al., 2002).

As the market become more competitive, it requires faster response with an effective solution to consumers. However, for the companies, problems are R\&D cost and time. Indeed, companies are finding it increasingly difficult to justify investments in innovation. The open business models address issues relates to problems that companies are facing by leveraging external research-and-development resources to save time and money in the innovation process. Henry Chesbrough notes that there is a paradigm shift 
in how companies commercialize industrial research.

"Today, the former leading industrial enterprises are encountering remarkably strong competition from many newer companies. These newcomers overtook the incumbent firms with little or no basic research of their own: Intel, Microsoft, Sun, Oracle, Cisco, Genentech, Amgen, Genzyme. These companies have been very innovative, but they achieved their innovative success with the research discoveries of others. And there is a legion of other, even newer companies waiting to supplant these firms, should the opportunity arise."5)

Knowledge production through investments in R\&D has been dominated by secretive and self-contained in-house processes to keep it proprietary. However, this negative perception of knowledge spillovers between firms and their environment is fading as recent literature has pointed towards the merits of acquiring external knowledge (Tsang, 2000) and moving from "research and develop" towards "connect and develo p"6)(Huston and Sakkab, 2006).

\subsection{Hypotheses}

Business model plays a key role in achieving business potential through research and development (R\&D). The purpose of open/closed business models concept has been defined by emphasizing value creation as a part of managing technology commercialization. Figure 1 suggests a number of possible factors that defines the characteristics of open/closed business models through assessing business models of the firms. The possible factors are: (1) Technology development time (2) The level of IP exploitation (3) Percentages of sales (Product<1yr/4yrs) (4) Size of the firms (5) R\&D Intensity. By accessing business models of the firms, not only firms with open business model or closed business model have been distinguished with its relationship with five factors, but also how difference in business models allows the firm to flank or attack its competitors, reduce costs, improve quality, absorb new technologies, expedite learning from customers, and improve new market performance. The hypothesized relationships are illustrated in Figure 1.

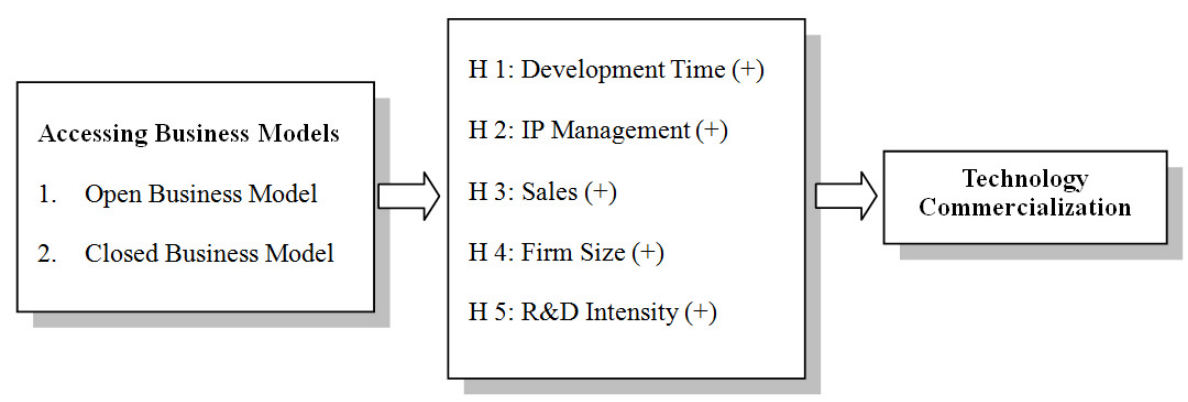

Figure 1. Conceptual Model of the Implications of Business Models

5) Chesbrough, H.W. Managing Open Innovation. Research-Technology Management, 2004: 23-26 [Jan-Feb]

6) The concept "Connect and Develop" drawn by P\&G is about finding good ideas and brings them in to enhance and capitalize on internal capabilities. 
Due to shorter product life cycle, many products in mature industries are revitalized by product differentiation and market segmentation. Indeed, organizations increasingly reassess product life cycle costs and revenues due to time available to sell a product and recover the investment shrinks. The combination of rising development costs and shortening market windows compresses the economics of investing in innovation, reducing the company's ability to earn a satisfactory return on its innovation investment (Chesbrough, 2006). Open business models attacks the cost side and revenue side of the problem. It attacks the cost side of the problem by leveraging external research-and-development resources to save time and money in the innovation process (Chesbrough, 2007). It also attacks the revenue side. P\&G, for instance, is creating new brands by licensing technologies from other companies around the world, resulting in products like the SpinBrush, a battery-operated toothbrush, which generated first year sales of \$200 million (Chesbrough, 2007). It demonstrates, depends on the level of exploiting IP, how IP management can bring profits to the companies. Many studies claimed that internal technology assets were opened primarily to attain additional revenue. Thus, Chesbrough suggests that the combination of leveraged cost and time savings with new revenue opportunities confers powerful advantages for companies willing to open their business models.

Langfield-Smith and Greenwood (1998) state that collaboration helps to develop new products and processes, improves quality, and reduces lead times. Thereby, R\&D organizations no longer need to be confined by the constraints of internal resources and lengthy innovation processes; instead, R\&D leaders can accelerate the time to market by creating a new, virtual organization that leverages technology to create virtual processes across a network of both internal and external strategic partners (Holtzman, 2008). Indeed, best practice companies are building integrated networks through acquisitions, strategic alliances and cross-industry collaboration with the purpose of being mutually beneficial and protected. The main strategy for maintaining a competitive advantage is to insulate the innovations through leveraging the organization's unique technical skill sets. These organizations have empowered a core group of key senior executives from R\&D, Marketing, Sales, Finance, and Operations to review and expedite high potential opportunities. This cross-functional group is given clearly defined roles and responsibilities, processes, tools and metrics which track progress and measure success. These types of empowered executive groups are critical to ensure timely feasibility approval. They meet regularly to assess and approve ideas generated either internally or through the alliance network.

Kimberly Clark has formed a "Global Intellectual Asset Team" which is responsible for managing the end-to-end intellectual assets process at business and enterprise levels. This team finds potential partners, negotiates deals, and manages the relationships. They are also responsible for determining the appropriate business model to most effectively develop and capitalize on the potential innovation. Since shifting to an open innovation approach, the company has reduced their time to market by 30\% (Holtzman, 2008). Thus, the following hypotheses have been proposed.

H1. The firm's degree of openness in its business model positively influence the development time of R\&D

H2. The firm's degree of openness in its business model positively influence the level of exploiting IP 
A central component in the movement toward open or interactive innovation models is a change in the way firms go about searching for new ideas and technologies for innovation (Laursen and Salter, 2006). Laursen and Salter (2006) explores the relationship between the openness of firms' external search strategies and their innovative performance by analyzing 2,707 UK manufacturing firms, theorizing that "the deeper and wider the search, the better the results attained from technological development." Analysis of business performance through technology development was divided into (1) sales contributions from the development of the world's first products in their category (2) sales contribution from the development of the company's own first products (3) sales contribution from improvement on existing products. The scope of open search was measured by the breadth (represented by the number of external information sources searched) and the depth (represented by the number of external information sources highly used by other companies). Based on the UK Innovation Survey, they used the Log-Tobit model and concluded that open search enhances the performance of technology development. More specifically, depth of search promotes drastic innovation, while breadth of search promotes gradual innovation.

Instead of exploring the relationship between the openness of firms' external search strategies and their innovative performance, studies from Faems, Looy and Debackere (2005) and Nieto and Santamaria (2007) focused on the impact of open innovation. The study of Faems et al. analyzed the effects of inter-firm $\mathrm{Co}^{-}$ operation on innovation in group of Belgian manufacturers. It tested the following three hypotheses regarding open cooperation: (1) businesses pursuing collaboration with a diverse range of organizations will achieve higher innovation performance; (2) "exploitative" collaboration will improve existing technologies and products alike; and (3) "explorative" collaboration will produce favorable effects for development of new technologies and products. To verify the hypotheses, the study used the 1997 Community Innovation Survey of 1,377 Belgium manufacturers. To measure the degree of innovation performance, the study used the contribution of the resulting products to overall company sales. The diversity of cooperation among organizations was measured by an index comprising (1) other departments inside a company (2) rival companies (3) customers, (4) consulting firms (5) suppliers (6) universities and (7) research institutes, on a scale of one to seven. "Exploitative" cooperation was determined by the presence of cooperative activities with customers and suppliers on a scale of one to ten, while "explorative" cooperation was measured by the presence of cooperative activities with universities or research institutes on a scale of one to ten. The control variables were firm size, appropriation efforts, affiliation with multinationals, degree of R\&D intensity, and an industry dummy variable etc. sales growth through product development and improvement increased along with growth in the degree of collaboration. The division between exploitative collaboration and explorative collaboration also was found to be valid.

Lichtenthaler (2005, 2007) conducted a survey with 154 European companies in order to analyze the performance, functions, and management of external commercialization activities. The study showed that sales revenue created by external commercialization had a positive relation with operating profits. However, only $40 \%$ of respondents posted growth in income from external commercialization, indicating that only a handful of companies manage to carry it out successfully.

In a survey of 5,455 Canadian manufacturing firms, Amara and Landry (2005) evaluated the hypothesis 
that the more diversified information sources are, the higher the innovation novelty becomes. This study categorized the degree of technological innovation into three levels of (1) first-in-the-world development, (2) first-in-the-country development, and (3) first-in-the-company development. Information sources were categorized into four categories: internal sources, markets, research institutes, and generally available information. Control variables were state-sponsored programs, the competition index, firm size, R\&D investment, and other innovation activities, etc. Based on the Canada Innovation Survey of 1999, the study concluded, using a multi variate LOGIT model, that the more information sources the businesses sought, the higher the level of technological novelty they achieved. Therefore, the following hypothesis has been proposed.

H3. Companies that have openness in its business model positively influence the percentage of firm's total sales from new products

Nieto and Santamaria's study (2007) analyzed the impact of R\&D collaboration networks on technology innovation among Spanish manufacturers. Their study focused on analyzing the impact of collaboration activities, continuity in collaboration and the number of collaboration partners on the degree of innovation. Control variables included firm size, R\&D intensity, export intensity, and industrial characteristics. To analyze the impact of past collaboration activities on current performance, this study used the Lagged model for all independent variables. This study used panel data (1998-2002) concerning Spanish manufacturers, and employed the bivariate probit model as a test method. Collaboration activities and continuity were found to result in a higher degree of innovation. Among the collaboration partners, suppliers contributed most to the degree of innovation, followed by customers and research institutes. Collaboration with rival companies, however, showed no positive influence on the degree of innovation. Among the control variables, R\&D intensity and export intensity were found to exert a positive influence. External commercialization has occurred in the real world even before studies were undertaken, and some successful cases like those of IBM have already been noted (Klein, 2003; Chesbrough, 2007).

R\&D intensity and marketing expenses are the two major business decisions that critically affect the firm's performance while performance implications of the two strategic decisions are still unclear and vary according to performance measures and possibly differ from industry to industry (Lin et al., 2006). However, R\&D intensity of a firm signifies the strategic importance of innovation to the firm. Although a high level of R\&D intensity does not guarantee the generation of successful innovations, firms that invest heavily in R\&D are more likely trying to compete on the basis of innovativeness and technology breakthrough (O'Brien, 2003).

Lichtenthaler and Ernst's study (2008) considers inward and outward technology transactions as the main directions of open innovation. Data from a survey of 154 industrial firms are used to test three hypotheses relating technology aggressiveness, external technology acquisition, and external technology exploitation (Lichtenthaler et al., 2008). The result shows that there is a significant and positive effect of firm size, which means larger firms acquire more technology from external sources than smaller firms. Moreover, 
there is a significant and positive influence of R\&D intensity (Lichtenthaler et al., 2008). Lichtenthaler and Ernst suggest that as external technology exploitation has become a broader trend only in recent years, it is still driven by large pioneering firms, which have a larger technology portfolio than smaller companies. In addition, while on OECD report found a positive correlation between changes in business-sector R\&D intensity and multifactor productivity growth during the 1980s and 1990s in the OECD area, the fact that Japan recorded a decline in Multi-factor productivity (MFP) growth despite higher R\&D spending suggests that its investment in innovation was less efficient (OECD, 2001).

Lin, Lee, Hung (2005) explores how technology-based firms deploy their R\&D and marketing resources for commercializing their technology assets. Especially, they examine the main effects of R\&D intensity, knowledge stocks, and commercialization orientation on firm performance as well as the interaction effects among the above variables. The data was collected from the US patent and financial data of 258 US-based technology public firms. It tested the following five hypotheses regarding commercialization: (1) The R\&D intensity of a technology firm positively influences the firm's financial performance (2) The commercialization orientation of a technology-based firm positively influences the firm's performance (3) R\&D intensity and commercialization orientation interact positively in influencing the performance of a technology-based firm (4) The knowledge stocks of a technology-based firm positively influence its performance (5) Commercialization orientation and the knowledge stocks interact positively in influencing the performance of a technology-based firm. Their result suggests that firms in different technology categories should have different technology commercialization strategies. Especially, they found out that sales and R\&D expenditures can be complementary to each other and the interaction effect of R\&D intensity and commercialization orientation is found to be positive and significant.

H4. Companies that have openness in its business model positively influence the size of the firms

H5. Companies that have openness in its business model positively influence the R\&D intensity of a firm

\section{Method}

\subsection{Sample and Data Collection}

In a recent literature review (Chesbrough, 2006), the business model framework (BMF) has been introduced. Chesbrough suggested that six kinds of business models undifferentiated (Type 1), differentiated (Type 2), segmented (Type 3), externally aware (Type 4), integrated (Type 5), and adaptive (Type 6) represent the innovation process and IP management aspects associated with each type of the model (Chesbrough, 2006). The theoretical model and the hypotheses are entirely based on the insight from prior research of open innovation. However, no prior research in the literature takes this perspective to examine the effectiveness of open business models in $R \& D$ performance.

To test the hypotheses, data were collected using via e-mail and fax. Small and medium-sized (less than 
300 employees) and large industrial firms were chosen for this study. The data for the analysis are drawn from the survey where it was implemented in 2008. Types of questions used in open innovation survey are described in APPENDIX A and B. The survey was sent to 125 business units in South Korea in October 2008. The open innovation survey drew responses from 30 researchers and directors from R\&D division of the firms, corresponding to a response rate of $24 \%$. Of the 40 questionnaires, data were sufficiently complete from 30 firms. Despite the assurances of complete anonymity and confidentiality, however, some of the firms did not include their name of the company or sales of main products. If the confidential nature of the questions in the survey is taken into account, this response rate can be considered high. A profile of the sample shows a reasonable spread of industrial firm size: small and medium-sized firms (43\%) and large firms (57\%).

\subsection{Classifications}

Using the open innovation survey, different types of business models for small and medium-sized firms and large firms in South Korea were determined. Table 1, suggested by Henry Chesbrough, lists all 20 questions for determining types of business models for manufacturing firms. Each firm was asked to indicate on a five-point scale the degree of recognition for each source. On the survey, the questions are grouped together under 6 different headings (Type 1: Undifferentiated, Type 2: Differentiated, Type 3: Segmented, Type 4: Externally aware, Type 5: Integrated, and Type 6: Adaptive).

Table 1. Diagnostic Questions for Assessing Business Models

\begin{tabular}{|c|c|}
\hline \multicolumn{2}{|c|}{ Diagnostic Questions } \\
\hline \multirow{4}{*}{$\begin{array}{l}\text { Type } 1 \\
\text { (Undifferentiated) }\end{array}$} & 1. Is there anything that differentiates this business from its competitors? \\
\hline & 2. Why do customers buy from us? \\
\hline & 3. Why do customers leave us? \\
\hline & 4. What control do we have over the future direction of our business? \\
\hline \multirow{3}{*}{$\begin{array}{l}\text { Type } 2 \\
\text { (Differentiated) }\end{array}$} & 1. Do we earn a price premium for our product or service? \\
\hline & 2. Can we sustain our differentiation over time? For how long? \\
\hline & 3. Are we likely to develop a second successful offering? When? \\
\hline \multirow{4}{*}{$\begin{array}{l}\text { Type } 3 \\
\text { (Segmented) }\end{array}$} & 1. Are we an engineering-driven company? \\
\hline & 2. Have we created new market segments, or did our customers find us? \\
\hline & 3. Can we further segment our markets? \\
\hline & 4. Can we extend our markets? \\
\hline \multirow{3}{*}{$\begin{array}{l}\text { Type } 4 \\
\text { (Externally } \\
\text { aware) }\end{array}$} & 1. Do we look outside regularly for new ideas and technologies? \\
\hline & 2. Do our key customers and suppliers know about our future road maps? \\
\hline & 3. Is marketing an equal partner in the innovation process \\
\hline \multirow{3}{*}{$\begin{array}{l}\text { Type } 5 \\
\text { (Integrated) }\end{array}$} & 1. Is our business model widely understood within our company? \\
\hline & 2. Do our key customers and suppliers share their road maps with us? \\
\hline & 3. Is innovation managed as a business or as a technology function? \\
\hline \multirow{3}{*}{$\begin{array}{l}\text { Type } 6 \\
\text { (Adaptive) }\end{array}$} & 1. Can we direct the future evolution of our markets? \\
\hline & 2. Will customers and suppliers fit their business models to ours? \\
\hline & $\begin{array}{l}\text { 3. Do other companies routinely invest in projects that require our technology as a } \\
\text { platform? }\end{array}$ \\
\hline
\end{tabular}


Table 2 shows the results for the entire range of questions for manufacturing firms in South Korea. Overall, 4.1 on average, the results indicate that majority of large firms have business model type 4 (Externally aware) whereas many small and medium-sized firms have business model type 1 (undifferentiated) with 4.08 on average. As might be expected, large firms have started to open itself to external ideas and technologies in the development and execution of the business, an important distinction from the type 3 business model (Chesbrough, 2006). However, small and medium-sized firms are in the phase where they do not have distinct business model and lack a process for managing one.

Table 2. The Business Model Assessment of Korea Manufacturing firms, year $2008(n=30)$

\begin{tabular}{|c|c|c|c|}
\hline Type & Business Model & Mean & Std. Deviation \\
\hline \multirow{6}{*}{ Large Firms } & Type 1 & 3.911765 & 0.672804163 \\
\hline & Type 2 & 3.920588 & 0.712859301 \\
\hline & Type 3 & 3.730588 & 0.626373197 \\
\hline & Type 4 & 4.097059 & 0.918557053 \\
\hline & Type 5 & 3.442353 & 0.864230361 \\
\hline & Type 6 & 3.568235 & 0.653722373 \\
\hline \multirow{6}{*}{$\begin{array}{l}\text { Small and medium-sized } \\
\text { Firms }\end{array}$} & Type 1 & 4.076923 & 0.400320385 \\
\hline & Type 2 & 3.949231 & 0.606595163 \\
\hline & Type 3 & 3.788462 & 0.267047004 \\
\hline & Type 4 & 3.537692 & 0.751633264 \\
\hline & Type 5 & 3.076923 & 0.492432476 \\
\hline & Type 6 & 2.924615 & 0.564012639 \\
\hline
\end{tabular}

\section{Measures}

To ensure reliability of the constructs, reliability analyses were carried out. The six types of business model, as classified in the previous section, are utilized for distinguishing open business model impact on technology commercialization.

\subsection{Independent Variables}

Six types of business model can be divided into two groups. Type 1, type 2, and type 3 are in the category of closed business model whereas open business model includes type 4, type 5 and type 6 . Type 1 (undifferentiated) business model is a four-item scale (Cronbach's alpha=.77) assessing appropriate business model as perceived by the respondents. These four five-point scale items reflect the degree to which the companies are capable of differentiate their business from its competitors, reasoning out why customers buy from them or leave them and knowing what control they have over the future direction of their 
business. Exploratory factors analysis supports only one factor and accordingly this study average the four items as an overall assessment measure of type1. Type2 (differentiated) business model is a three five-point scale item (Cronbach's alpha=.66) indicating the extent to which the companies are capable of earning a price premium for their product or service, sustaining their differentiation over time, and developing a second successful offering. Exploratory factors analysis supports only one factor and accordingly this study average the three items as an overall assessment measure of type 2. Type3 (segmented) business model is a four five-point scale item (Cronbach's alpha=.53) indicating the extent to which the companies are capable of creating new market segments and extending their market. There liability of the variable of type 3 business model ( $a=0.53$ ) is somewhat lower below 0.7 but is merely acceptable (Hair et al., 1998).

Starting from business model type 4, companies are starting to open itself to external ideas and technologies in the development and execution of the business (Chesbrough, 2006). Type4 (externally aware) business model is a three five-point scale item (Cronbach's alpha=.86) indicating the extent to which the companies are looking outside regularly for new ideas and technologies. Also, in this business model, customers and suppliers know about company's future roadmaps and marketing department involves in the innovation process. Type5 (integrated) business model is a three five-point scale item (Cronbach's alpha=.70) where it has to satisfy three factors: innovation management, roadmaps, and understanding of business model. Type6 (adaptive) business model is a three five-point scale item (Cronbach's alpha=.74) where it asks companies' capability of directing the future evolution of their markets, matching business model to customers and suppliers, and supporting their technology as a platform where companies routinely invest in projects.

\subsection{Dependent Variables}

To capture a firm's open innovation effect within the each types of business model, two variables, development period (development period) and percentage of sales from products (Sales (Product<4yrs)), were used. Following the literature (Buzzell and Gale, 1987), the survey asked managers, 'Once your company has developed a new product, how long on average does it take your company to introduce it to the market?' Indeed, for the development period, due to the confidentiality of this information in most firms, development period was measured in the following six categories: 1yr 2yrs, 2yrs 3yrs, 3yrs 4yrs, 4yrs 5yrs, 5 yrs 6yrs, and over 6yrs.

Several concepts have been discussed in the literature for capturing innovation success (for an overview see OECD, 2005). Some focus on innovation inputs (R\&D expenditure), while others point towards the consequences of innovation activities, e.g. patents, new processes and products. The latter perspective has been chosen. While each new product may be valuable in itself, firm success heavily depends on its market acceptance. Hence, this research conceptualize innovation success as the share of sales achieved with products new to the firm (Laursen and Salter, 2006). However, due to the high p value for new product (Sales (Product<1yr)), percentage of sales from products that are less than four years (Sales (Product<4yrs)) has been chosen. Thus, it can be compared with each type of business model to demon- 
strate innovative firms have higher percentage of sales from new products rather than from products that are launched 4 years ago.

\subsection{Control Variables}

Furthermore, we add control variables for several other factors that may influence the estimation results. The relationship between firm size and innovation capability has long been a debated issue in the innovation literature (Freeman and Soete, 1997). Most empirical studies of firm performance include firm size as a control variable or an independent variable. Moreover, firms may suffer from a liability of size or smallness. Thus, SMEs and large firms are distinguished by number of full-time employees in the company. In addition, because of the higher commercialization potential, $R \& D$ intensity, i.e., R\&D expenditure as a percentage of sales, has been considered as another control variable to reflect the size of a firm's technology portfolio.

The study controlled also for IP exploitation types, which could determine the companies' IP strategy. Higher exploitation of IP might encourage companies to view it as another class of corporate asset or revenue generation opportunities. Thus, it was measured in the following six categories: 1. NA, 2. Reactive, 3. Defensive, 4. Enabling asset, 5. Financial asset, and 6. Strategic asset. Moreover, open innovation division was measured in the following three categories as a control variable: 1. NA, 2. Yes (subdivision of OI), and 3. Yes (main division of OI).

\section{The Impact of Open Innovation}

The Pearson product-moment correlation coefficient (sometimes referred to as the MCV or PMCC, and typically denoted by $r$ ) was used for analyzing the impact of open innovation. Pearson's correlation $\mathrm{co}^{-}$ efficient (named after Karl Pearson, 1857-1936) is a number between -1 and 1 that measures the strength of a linear relationship between two continuous variables. It is a common measure of the correlation (linear dependence) between two variables $\mathrm{X}$ and Y. However, in the presence of extreme outlier, or in the presence of a non-linear relationship, Pearson's $r$ may not detect a significant correlation.

Descriptive statistics are given in Table 3 with a relatively high mean of 3.33, which reflects that technology development time is usually considered a major challenge in technology commercialization. In addition, the data shows that the firms in the sample have an average of 2.81 in its business model. Thus, the business model of Korea firms is mostly in between Type 2 and Type 3. With a mean of 2.56 on a five-point scale, the firms in the sample have relatively high percentage of sales from the products that are launched less than four years. However, the firms with a mean of 2.48 have relatively lower percentage of sales from the products that are launched less than a year. 
Table 3. Descriptive Statistics

\begin{tabular}{llllll}
\hline Variables & N & Mean & S.D. & Minimum & Maximum \\
\hline Development period & 30 & 3.33 & 1.73 & 1 & 6 \\
\hline Sales (Product $<$ 4yrs) & 27 & 2.56 & 0.75 & 1 & 5 \\
Sales (Product $<$ 1yr) & 27 & 2.48 & 0.70 & 1 & 5 \\
\hline R\&D Intensity & 29 & 2.21 & 1.05 & 1 & 5 \\
Business Model & 26 & 2.81 & 1.65 & 1 & 6 \\
Firm Type & 30 & 1.43 & 0.50 & 1 & 2 \\
IP Management & 30 & 3.20 & 1.27 & 1 & 6 \\
\hline Open Inmovation Div. & 30 & 1.90 & 0.71 & 1 & 3 \\
\hline
\end{tabular}

\subsection{The Cross Impact of Open Innovation on Variables}

Table 4 presents correlations, means and standard deviations for the variables under consideration. This study attempts to understand the roles of open business model in technology commercialization. Table 4 suggests that the correlation among the dependent and independent variables were consistent with expectations. The data shows significantly positive and negative correlations between business models and nearly all variables. The analyses showed that business model was negatively and significantly related to the development time $(\mathrm{p}<0.01)$ of technology, which means more openness in its business model decreases the development time. These results supported Hypothesis 1 . Percentage of sales from the products that are launched less than four years $(\mathrm{p}<0.10)$ was negatively and significantly related to the business models. However, percentage of sales from the products that are launched less than a year $(\mathrm{p}<0.05)$ was positively and significantly related to the business model. The result shows how openness in its business model affects sales from new products. Thus, these two results supported Hypothesis 3.

Firm type $(\mathrm{p}<0.05)$ was negatively and significantly related to the business model whereas R\&D intensity ( $\mathrm{p}<0.05$ ) was positively and significantly related to the business model. As the firms get bigger, there is more openness in its business model with the increase in R\&D intensity. These results supported Hypothesis 4 and Hypothesis 5. Moreover, the level of IP management was positively and significantly related to the business model meaning there is higher level of exploiting IP with open business model. Accordingly, the result supported Hypothesis 2. 
Table 4. Descriptive Statistics and Correlations among Variables

\begin{tabular}{|c|c|c|c|c|c|c|c|c|c|}
\hline Variables & Mean & S.D. & 1 & 2 & 3 & 4 & 5 & 6 & 7 \\
\hline Development period(1) & 3.33 & 1.73 & & & & & & & \\
\hline Sales (Product< $<$ yrs)(2) & 2.56 & 0.75 & 0.12 & & & & & & \\
\hline Sales (Product $<$ 1yr)(3) & 2.48 & 0.70 & 0.07 & -0.31 & & & & & \\
\hline R\&D Intensity(4) & 2.21 & 1.05 & -0.27 & $-0.56^{* * *}$ & $0.40^{* *}$ & & & & \\
\hline Business Models(5) & 2.81 & 1.65 & $-0.60 * * *$ & $-0.38^{*}$ & $0.52^{* *}$ & $0.53^{* * *}$ & & & \\
\hline Firm Type(6) & 1.43 & 0.50 & 0.30 & 0.28 & -0.03 & $-0.32 *$ & $-0.40^{* *}$ & & \\
\hline IP Management(7) & 3.20 & 1.27 & -0.13 & -0.15 & 0.32 & 0.25 & $0.54^{* * * *}$ & $-0.41^{* *}$ & \\
\hline Open Innovation Div.(8) & 1.90 & 0.71 & 0.06 & 0.01 & 0.24 & 0.31 & 0.30 & -0.07 & $0.40^{\text {*** }}$ \\
\hline
\end{tabular}

Pearson correlations; One-tailed t-test applied. $* \mathrm{p}<0.10 ; * * \mathrm{p}<0.05 ; * * * \mathrm{p}<0.01$

\subsection{The Impact of the Development Times and Sales on Open Innovation}

As we noted in the introduction on the key issue in preventing the companies from achieving higher returns, from the BCG Innovation 2008 survey, executives most commonly cited overly lengthy development times. In reflection upon stated problem, we wanted to see how six different types of business models get benefit from overly lengthy development times and its affect in sales. Thus, in Table 5, models 1 and 2 , the development period and sales (product<4yrs) have been used to capture open innovation effect of the each type of business model. Again, the result shows that there are significantly positive effects of firm size and negative effects of R\&D intensity. Model 1 shows a significantly positive effect of Type 3 (Segmented), Type 4 (Externally aware), and Type 5 (Integrated), which, however, disappears when introducing other dependent variable. In model 1, Type 1 (Undifferentiated), Type 2 (Differentiated), and Type 6 (Adaptive) do not have a significant effect.

In model 2, the result shows that R\&D intensity and IP management have negative effects whereas firm size have positive effect on sales (product<4yrs). Interestingly, both Type 1 and Type 2 are positively related to sales from the products that are less than 4 years. These findings moderately support Hypothesis 3 and indicate that in general companies with closed business model would achieve a higher percentage of sales from the products that are launched less than 4 years. 
Table 5. Results of OLS7) Analyses

\begin{tabular}{lll}
\hline Variables & Model 1 & Model 2 \\
\hline Dependent variable & $\begin{array}{l}\text { Development } \\
\text { period }\end{array}$ & Sales (Product $<$ 4yrs) \\
\hline R\&D Intensity & $-0.27^{*}(.30)$ & $-0.56^{* * *}(.12)$ \\
\hline Firm Type & $0.30^{*}(.74)$ & $0.39^{* *}(.33)$ \\
\hline IP Management & $-0.12(.31)$ & $-0.29^{*}(.13)$ \\
\hline Open Innovation Div. & $0.06(.45)$ & $0.00(.24)$ \\
\hline Business Model & & \\
\hline Type 1 (Undifferentiated) & & \\
\hline Type 2 (Differentiated) & $0.05(.72)$ & $0.31^{*}(.29)$ \\
\hline Type3 (Segmented) & $-0.02(.57)$ & $0.28^{*}(.23)$ \\
\hline Type4 (Externally aware) & $-0.33^{* *}(.89)$ & $0.25(.38)$ \\
\hline Type5 (Integrated) & $-0.53^{* *}(.72)$ & $-0.17(.33)$ \\
\hline Type6 (Adaptive) & $-0.59^{* * *}(.85)$ & $0.01(.37)$ \\
\hline R2 & $-0.19(.64)$ & $-0.28^{*}(.26)$ \\
\hline R2 adjusted & 0.78 & 0.81 \\
\hline F & 0.61 & 0.66 \\
\hline
\end{tabular}

$* \mathrm{p}<0.10 ; * * \mathrm{p}<0.05 ; * * * \mathrm{p}<0.01$

Unstandardized coefficients with standard errors in parentheses

\section{Discussion and Implication}

\subsection{Major Findings}

This research has examined the impact of open innovation business model in technology commercialization by applying the data from 30 companies of manufacturing firms in South Korea. The findings provide support for distinguishing five hypotheses relating to development time, IP management, sales, firm size and R\&D intensity. The result shows that openness in its business model is positively associated with successful technology commercialization. The major findings and the implications are: First, the results of the regression analysis indicate that in general as the business model gets more open, development period of technology will be more favorable which gets benefit from rising costs of innovation. Moreover, as the business model gets more open, large portion of sales are created from new products. Thus, problem of shorter product life in the market which affects large portion of market revenue can be solved through

7) The method of calculating the regression coefficient (the slope) is called ordinary least squares, or OLS. OLS estimates the slope by minimizing the sum of squared differences between each predicted $(a X+b)$ and the actual value of $Y$. One reason for squaring these distances is to ensure that all distances are positive. 
open business model. Secondly, the findings indicate that in general R\&D intensity, firm size and the level of IP management affect determination of business model type. It is also noted that companies need to increasingly address their external technology exploitation process instead of focusing on their internal innovation processes.

Empirically, this article recognizes and measures the degree to which firms follow the open innovation paradigm regarding the acquisition and commercialization of technology assets; in contrast, prior works in this field are mostly based on theoretical considerations and case studies (Lichtenthaler, 2008b). Moreover, this study provides a richer understanding of the relationships among different types of business models while setting the stage for exploring their influence on technology commercialization. Another contribution is assessing business models of companies in the perspective of open and closed innovation. Furthermore, this study has analyzed the various formal and informal mechanisms that a firm can use to integrate their business model toward more open with its impact in technology commercialization.

\subsection{Theoretical and Managerial Implication}

The technological management literature shows that firms have great difficulty managing innovation that fall outside of their previous experience, where their earlier beliefs and practices do not apply (Chesbrough, 2002b). It is time for change where new business model for managing innovation is essential. This article has implications for research into the importance of having open business model for successful technology commercialization, in particular, through this research; it introduced one of the methods for fostering technology commercialization. In order for the firms to benefit from the external innovation, the organizations need to identify such innovations, maintain the absorptive capacity to understand them, and be able to combine such spillovers with firm specific internal innovation to produce a product tailored to the firm's specific needs (West \& Gallagher, 2006).

With regard to open/closed business model, the conceptual model integrates both theoretical and practical aspects to advance towards a practical theory of open innovation. The five hypotheses relating to development time, IP management, sales, firm size and R\&D intensity have shown that the level of closeness or openness in its business model deepens our understanding of R\&D management in profiting from open business model. Accordingly, the companies need to increasingly address their external technology exploitation process instead of focusing on their internal innovation processes by defining their present business model. Indeed, most companies find it very difficult to define their present business model, let alone handle more than one business model at the same time or develop a new innovative business model (Gerards, 1979; Collins \& Porras, 1994). Yet this is exactly where opportunities arise to create value for the company because a business model is by definition based on a company's unique core competencies, experience and innovative potential. Companies with an open innovation approach are fully aware of their dominant business model and can develop new ones if needed (Meer, 2007). They can value new innovative models proposed by outsiders and adopt them if they wish. But for most companies thinking in alternative business models is still a long way from home, as this research highlighted. 


\subsection{Limitation and Future Research}

This research benefits from the dataset covering the manufacturing firms in South Korea. However, all studies have limitations especially on the quantitative side that may provide opportunities for future research. First, our results are limited to the Korea context. Moreover, it does not cover all Korea manufacturing industries and the results may not apply to all sectors of the economy. Comparative studies from developed but also developing countries with different institutions and cultural norms could provide valuable new insights. Also, further research on open innovation processes is still necessary and essential in terms of method for creating innovation processes that enable a high degree of collaboration. Since, acquiring or searching external knowledge become important part of the innovation process, it could be interesting to investigate the companies that have succeeded as well as failures to understand enablers as well as barriers.

\section{Acknowledgements}

The authors thank Ulrich Lichtenthaler (WHU-Otto Beisheim School of Management) for his splendid and constructive comments on earlier versions of this article.

\section{APPENDIX}

\section{APPENDIX A: DIAGNOSTIC QUESTIONS FOR ASSESSING BUSINESS MODELS}

I. Undifferentiated (Type 1) (4 items, $a=0.77)$ (1=Strongly disagree, 5=Strongly agree)

(1) Is there anything that differentiates this business from its competitors?

(2) Why do customers buy from us?

(3) Why do customers leave us?

(4) What control do we have over the future direction of our business?

II. Differentiated (Type 2) (3 items, $\alpha=0.66$ ) (1=Strongly disagree, 5=Strongly agree)

(1) Do we earn a price premium for our product or service?

(2) Can we sustain our differentiation over time? For how long?

(3) Are we likely to develop a second successful offering? When?

III. Segmented (Type 3) (4 items, $\alpha=0.53)$ (1=Strongly disagree, 5=Strongly agree)

(1) Are we an engineering-driven company?

(2) Have we created new market segments, or did our customers find us? 
(3) Can we further segment our markets?

(4) Can we extend our market?

IV. Externally aware (Type 4) (3 items, $\alpha$ =0.86) (1=Strongly disagree, 5=Strongly agree)

(1) Do we look outside regularly for new ideas and technologies

(2) Do our key customers and suppliers know about our future roadmaps?

(3) Is marketing an equal partner in the innovation process

$V$. Integrated (Type 5) (3 items, $\alpha=0.70)(1=$ Strongly disagree, 5=Strongly agree)

(1) Is our business model widely understood within our company?

(2) Do our key customers and suppliers share their road maps with us?

(3) Is innovation managed as a business or as a technology function?

VI. Adaptive (Type 6) (3 items, a =0.74) (1=Strongly disagree, 5=Strongly agree)

(1) Can we direct the future evolution of our markets?

(2) Will customers and suppliers fit their business models to ours?

(3) Do other companies routinely invest in projects that require our technology as a platform?

$a=$ Cronbach's alpha

\section{APPENDIX B: THE OTHER MEASUREMENT ITEMS}

1. Initial development time of core products
(1) $1 \sim 2$ yrs
(2) $2 \sim 3$ yrs
(3) $3 \sim 4$ yrs (4) $4 \sim 5$ yrs
(5) $5 \sim 6$ yrs
(6) over 6 yrs

2. R\&D intensity of your company
(1) $1 \sim 3 \%$
(2) $3 \sim 6 \%$
(3) $6 \sim 9 \%$
(4) $9 \sim 12 \%$
(5) over $12 \%$

3. The level of IP management
(1) NA
(2) Reactive (3) Defensive (4) Enabling asset (5) Financial asset (6) Strategic asset

4. Percentage of sales from products (products $\langle 1$ yr)
(1) NA
(2) $0 \%$
(3) $1 \sim 49 \%$
(4) $50 \sim 99 \%$
(5) $100 \%$

5. Percentage of sales from products (products < 4yrs)
(1) NA
(2) $0 \%$
(3) $1 \sim 49 \%$
(4) $50 \sim 99 \%$
(5) $100 \%$

6. Open innovation division
(1) NA
(2) Yes (subdivision of $\mathrm{OI}$ )
(3) Yes (main division of $\mathrm{OI}$ ) 


\section{Size of the firm}
(1) Large firm
(2) Small and Medium Enterprise ( $<300$ employees)

\section{REFERENCES}

Amara, N., and Landry, R. 2005. "Sources of information as determinants of novelty of innovation in manufacturing firms: evidence from the 1999 Statistics Canada innovation survey." Technovation 25(3):245-259.

Banbury, C, and Mitchell, Wl. 1995. "The Effect of Introducing Important Incremental Innovations on Market Share and Business Survival.” Strategic Management Journal 16:161-182.

Brockhoff, K. 1999. "Technological Progress and the Market Value of Firms." International Journal of Management Reviews 1(4):485-501.

Buzzell, R. D, and Gale, B. T. 1987. The PIMS Principles-Linking Strategy of Performance. New York: Free Press.

Cabinet Office. 2005. White Paper on the National Lifestyle 2005. Tokyo: Perceptions and lifestyle of the childrearing generation.

Chesbrough, Henry. 2002. "Graceful Exits and Foregone Opportunities: Xerox's Management of Its Technology Spinoff Organizations.” Business History Review 76(4):803-838.

Chesbrough, Henry. 2003. Open Innovation: The New Imperative for Creating and Profiting from Technology. Boston, MA: Harvard Business School Press.

Chesbrough, Henry, and Richard, S. Rosenbloom. 2002. "The role of the business model in capturing value from innovation: evidence from Xerox Corporation's technology spin-off companies.” Industrial and Corporate Change 11(2):529-555.

Chesbrough, H. W. 2003. "The Era of Open Innovation." Sloan Management Review 44(3):35-41.

Chesbrough, H. W. 2006. Open Business Model. Boston, MA: Harvard Business School Press.

Chesbrough, H. W. 2007. "Why Companies Should Have Open Business Models." MIT Sloan Management Review 42:22-28.

Collins, J., and Porras, J. I. 1994. Built to Last: Successful Habits of Visionary Companies, 90-212. New York: Harper Business.

Faems, D., Van Looy, B., and Debackere, K. 2005. "Interorganizational collaboration and innovation: toward a portfolio approach.” Journal of Product Innovation Management 22(3):238-250.

Freeman, C, and Soete, L. 1997. The economics of industrial innovation, 3rd ed. Cambridge, MA: MIT Press.

Gerards, H. M. A. M. 1979. “Gedragsmodel voor middelgrote ondernemingen.” PhD diss., University Twente.

Hair, Jr J. F., Anderson, R. E., Tatham, R. C., and Black, W. C. 1998. Multivariate Data Analysis, Upper Saddle River, NJ: Prentice-Hall.

Holtzman, Y. 2008. "Innovation in research and development: tool of strategic growth." Journal of Management Development 27:1037-1052.

Huston, L, and Sakkab, N. 2006. "Connect and Develop." Harvard Business Review 84(3):58-66.

Andrew, James P. et al. 2007. "Innovation 2007: A BCG Senior Management Survey.” Boston Consulting Group. Accessed August 2007. https://www. bcg.com/documents/file15063.pdf

Joel, West, and Scott, Gallagher. 2006. Patterns of Open Innovation in Open Source Software. Open Innovation: Researching a New Paradigm, 82-106. Oxford: Oxford University Press.

Park, Jong Won. 2011. "IP Convergence \& Strategic Management of Intellectual Property Study - Apple’s Open Innovation Case." Hongik University Graduate School.

Kim, Kwang Soo, Choi, Sang Hak. 2011. "Research on different expectations on recognition of innovative activities." Journal of the Korea Society for Quality Management 39(1).

Kim, Moon Sun, Kim, Soo Jung, and Nam, Kyung H. 2012. "The Empirical Study on Relation between R\&D 
Innovation Capability and Performance in Knowledge-Based Service Firms." Journal of the Korean Society for Quality Management 40(4)

Kim, Yun Bae, Shin, Jun Seok, Joe, Geun Tae. 2013. "The Trend, Motivation and Hindrance of Open Innovation." Sungkyunkwan University Graduate School.

Langfield-Smith, K., Greenwood, M. 1998. "Developing cooperative buyer-supplier relationships: a case study of Toyota.” Journal of Management Studies 35(3):332-353.

Lichtenthaler, U. 2005. "External commercialization of knowledge: Review and research agenda." International Journal of Management Reviews 7:231-255.

Lichtenthaler, U. 2008. Open Innovation in Practice: An Analysis of Strategic Approaches to Technology Transactions, IEEE Trans, Eng. Manage 55(1):148-157.

Lichtenthaler, U., and Ernst, H. 2007. "External technology commercialization in large firms: results of a quantitative benchmarking study.” R\&D Management 37:383-397.

Lichtenthaler, U., and Ernst, H. 2008. "Opening up the innovation process: the role of technology aggressiveness." R\&D Management:1-17.

Lin, B., Lee, Y., and Hung, S. 2006. "R\&D intensity and commercialization orientation effects on financial performance." Journal of Business Research 59:679-685.

Magretta, J. 2002. "Why Business Models Matter." Harvard Business Review 80(5):86-92.

Meer, H. 2007. "Open Innovation- The Dutch Treat: Challenges in Thinking in Business Models." Creativity and Innovation Management 16(2):192-202.

Nevens, T. M., Summe, G. L., and Uttal, B. 1990. "Commercializing technology: what the best companies do?" Harvard Bus. Rev. 1990:154-163.

Nieto, M. J., and Santamaria, L. 2007. "The importance of diverse collaborative networks for the novelty of product innovation." Technovation 27(6-7):367-377.

O'Brien, Jonathan P. 2003. "The capital structure implications of pursuing a strategy of innovation." Strategic Management Journal 2003 24(5):415-31.

OECD. 2001. The New Economy Beyond the Hype-The OECD Growth Project. Paris.

OECD. 2005. Oslo Manual: Guidelines for Collecting and Interpreting Innovation Data. Paris.

Pohle, G., and Chapman, M. 2006. "IBM's global CEO report 2006: business model innovation matters." Strategy and Leadership 34(5):34-40.

Rigby, D., Zook, C. 2002. “Open-Market Innovation.” Harvard Bus. Rev. :80-89.

Teece, D. 1986. "Profiting from technological innovation: implications for integration, collaboration, licensing and public policy.” Research Policy 15(6):285-305.

Teece, D. J. 1998. "Capturing value from knowledge assets: the new economy, markets for know-how, and intangible assets." California Management Review 40:55-79.

Tsang, E. W. K. 2000. "Transaction Cost and Resource-Based Explanations of Joint Ventures: A Comparison and Synthesis.” Organizational Studies 21(1):215-242.

Yoon, Heon Deok, Yoon, and Sung, Jong Su. 2011. "The Effect of Business Ethics and innovative Tendencies on a Organizational Performance. - Focused on awareness of business ethics' moderating effect for ISO 26000' improvement of performance." Journal of the Korea Society for Quality Management 39(2). 